\title{
A General Method for Deciding the Input Filter Capacitance of Flyback Switching AC-DC Converter with Peak Current-Controlled Mode
}

\author{
Jiaxin Chen ${ }^{* * * *}$, Jianguo Zhu**, and Youguang Guo** \\ * College of Electromechanical Engineering, Donghua University, Shanghai 200051, China \\ ** Faculty of Engineering, University of Technology, Sydney (UTS), NSW 2007, Australia
}

\begin{abstract}
This paper presents a general method for deciding the input filter capacitance of flyback switching acdc converters with peak current-controlled mode. Firstly, a simulation model for flyback ac-dc converter is obtained by adding the rectifier and filter circuit to a flyback dc-dc converter model developed by the authors. The simulation results show that the processes of capacitor charging and discharging are independent, their boundary is near the maximal value of input voltage, and the part of flyback dcdc converter can be seen as an approximately constant power load. Secondly, an analytic model for deciding the input power of flyback dc-dc converter with rated load and different input dc voltages is presented. Furthermore, the effect caused by the parasitical parameters in the electronic parts is studied, and the corresponding analytical method for deciding the input filter capacitance is given. The effect on the capacitance caused by the control delay is analyzed qualitatively.
\end{abstract}

Index Terms--Analytic model, flyback switching ac-dc converter, input filter capacitance, numerical simulation model.

\section{INTRODUCTION}

Flyback switching ac-dc converter with peak currentcontrolled model is commonly used as small power converter because of its simple structure. A comprehensive analysis for improving its performance is always desirable, so a great amount of work has been done on the operational principle, design methodology, modeling, and control of the flyback converter [1-5]. As the converter often works in wide input alternating voltage such as 85 - $264 \mathrm{VAC}$, the input capacitance has heavy impact on the output capability and other electrical specifications of converter. The flyback converter is a highly nonlinear and complicated system, and little literature introduced about the method for deciding its parameters. Although some papers [3-4] presented empirical formulae or principle to decide the capacitance, they are not accurate enough to meet the requirement of power converter design yet. In the actual process of designing a converter, engineers have to apply large numbers of trials and errors, which are costly.

With the development of the technique of computer aided design (CAD), many problems in nonlinear systems can be solved, and some new physical rules may be

This work was partly supported by the Endeavour Australian Postgraduate and Postdoctoral Fellowships Program. obtained. In several current commercial CAD tools for control system design, Matlab/Simulink is one of the most widely used CAD systems for its convenience and strong performance. To analyze a nonlinear system, comparing with the analytic method, the numerical method based CAD often has higher accuracy but takes more time, and is harder to reveal the physical rules. As they are complementary, it is advantageous to obtain both of them for a system. For that, two methods for deciding the input filter capacitance of flyback switching ac-dc converters with peak current-controlled mode are introduced in this paper. Furthermore, the impact on the capacitance due to the parasitical resistance in the input circuit and the control delay is also analyzed.

\section{NUMERICAL METHOD FOR DECIDING THE INPUT FilTER CAPACITANCE IN FlybaCK AC-DC CONVERTER}

Fig. 1(a) shows the typical topology of a flyback ac-dc converter with peak current-controlled model, where the dashed line connects control block to the main circuit, $\mathrm{C}_{0}$ is the input filter capacitance, and $R_{0}$ is the parasitical resistance in the input circuit.

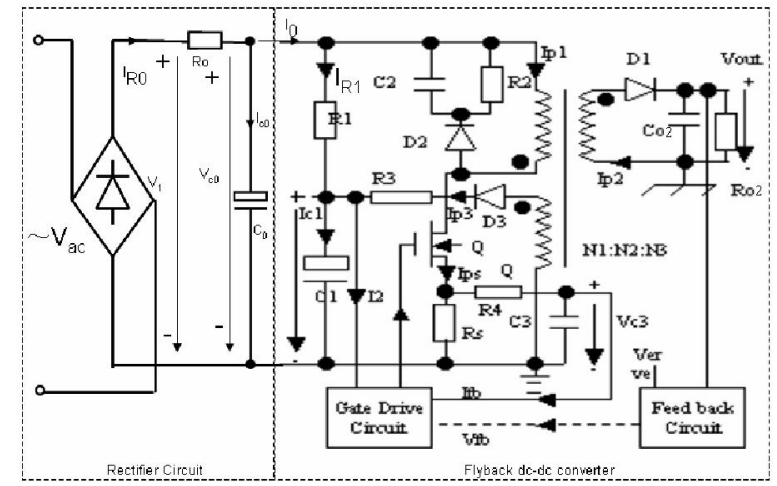

Fig. 1. Typical circuit of a flyback ac-dc converter

\section{A. Modelling the Flyback Switching AC-DC Converter}

Paper [1] introduced a simulation model of flyback dcdc converter in Matlab/Simulink surrounding. The circuit of flyback ac-dc converter (Fig. 1) can be divided into two parts as shown in two dashed frames separately: one is the rectifier, and the other is the flyback dc-dc converter. The complete simulation model of flyback acdc converter is obtained by only adding the model of rectifier circuit, as shown in Fig. 2, to that in [1], which is in the subsystem of flyback dc-dc converter. 


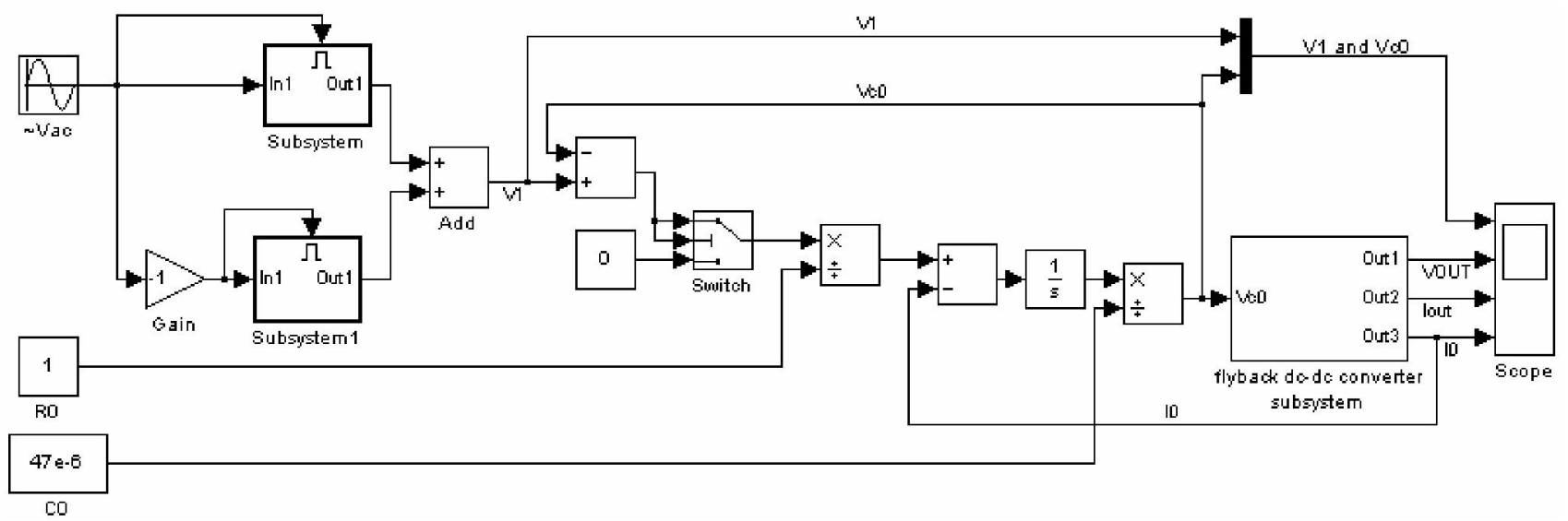

Fig. 2. Simulation model of the flyback ac-dc converter

\section{B. Performance Analysis}

The model shown in Fig. 2 is applied to the flyback switching ac-dc converter to analyze whether or not the value of the filter capacitance $\mathrm{C}_{0}$ can meet the requirement of the output ability. The major data of the converter include [1]: Input voltage: $\mathrm{V}_{\mathrm{ac}}=85-264 \mathrm{VAC} / 50$ $\mathrm{Hz}$; Nominal output voltage: $\mathrm{V}_{\text {out }}=5$ VDC; Rated output current: $\mathrm{I}_{\text {out }}=3.6 \mathrm{~A}$; Switching frequency: $\mathbf{f}=60 \mathrm{kHz}$; Peak value of the primary current: $\mathrm{I}_{\mathrm{plmax}}=0.89 \mathrm{~A}$; Input filter capacitance: $\mathrm{C}_{0}=47 \mu \mathrm{F}$; Parasitical resistance in the input circuit: $\mathrm{R}_{0}=1 \Omega$; Magnetic Core: EI25; Magnetic material: TDK PC40.

All the left parameters of electronic parts in the flyback dc-dc converters are the same as those in [1]. By putting all the parameters of electronic parts into the proposed simulation model and running the model in Matlab/Simulink surrounding, some important results are obtained and shown in Fig. 3(a)-(h).

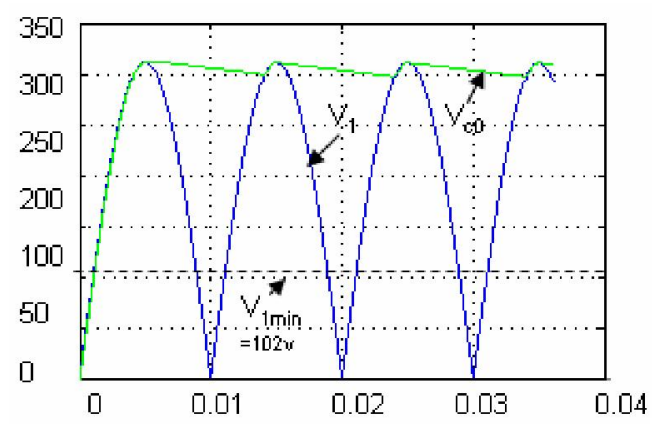

(a)

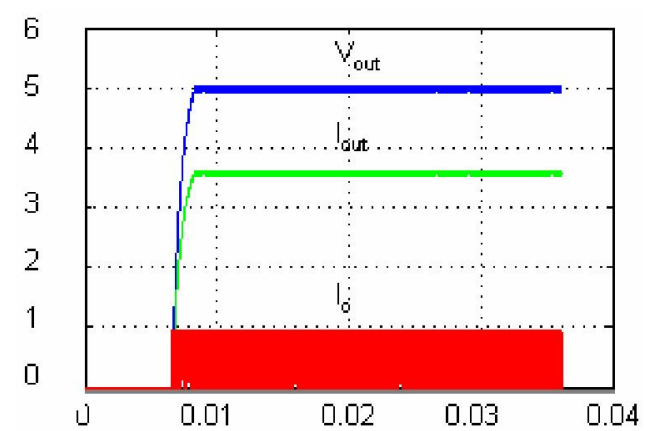

(b)

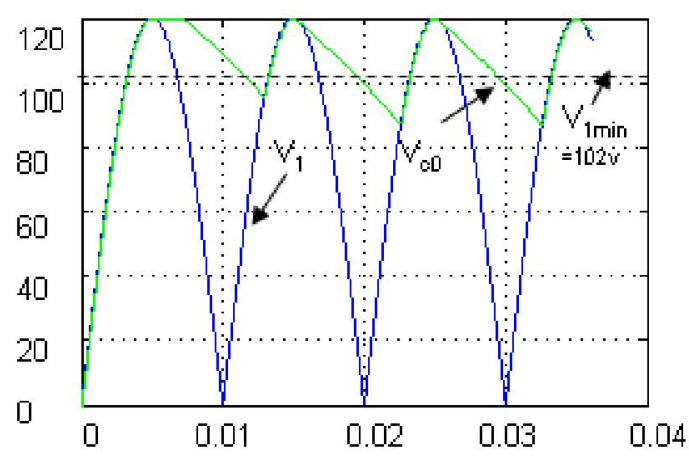

(c)

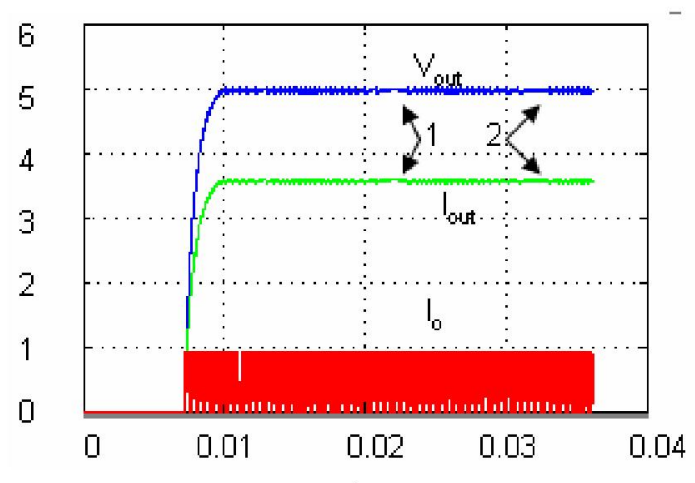

(d)

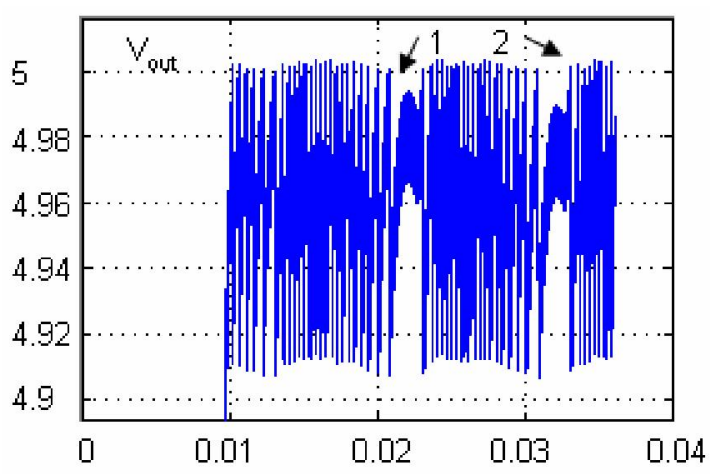

(e) 

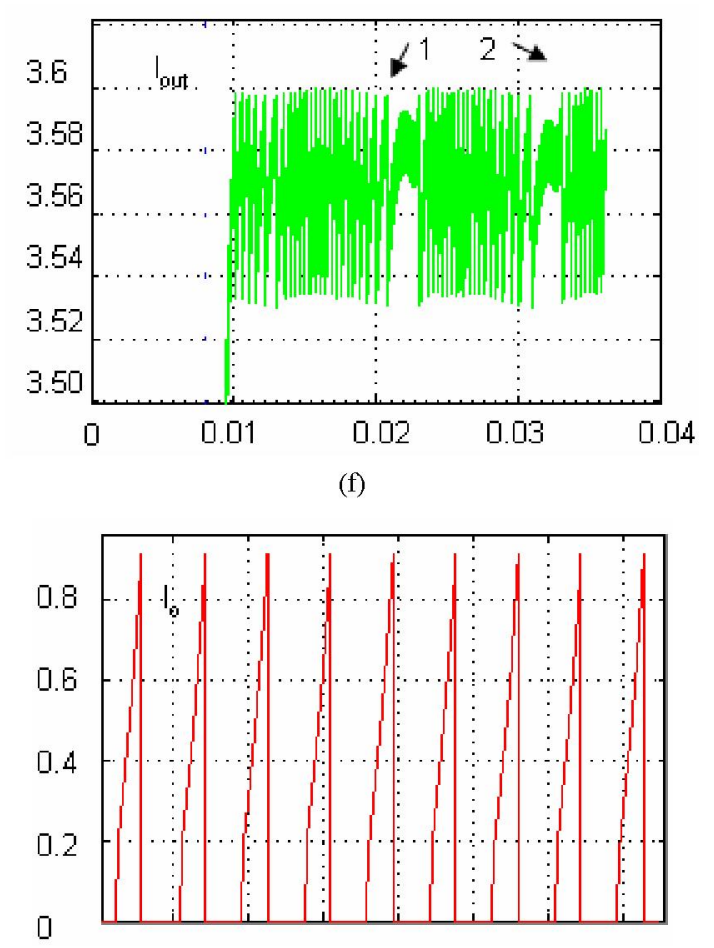

(g)

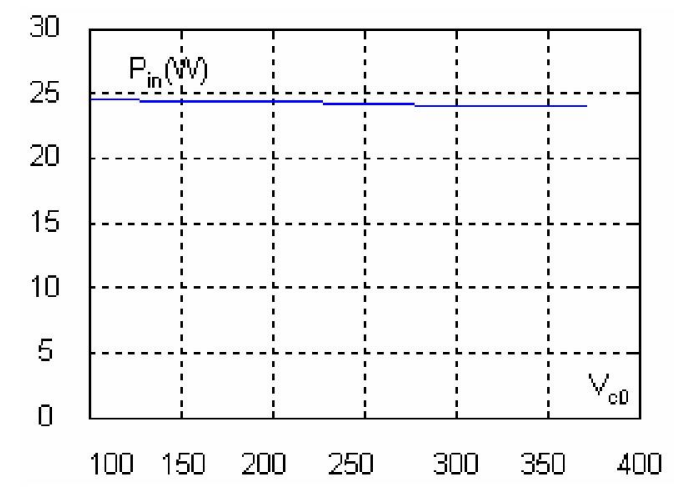

(h)

Fig. 3. Simulation results: (a) output voltage of rectifier $V_{l}$, and voltage across the capacitance $\mathrm{C}_{0}, V_{c 0}$ when the input voltage $V_{a c}=220 \mathrm{~V}$; (b) output voltage $V_{\text {out }}$, output current $I_{o u t}$, and input current $I_{\theta}$ of flyback dcdc converter when $V_{a c}=220 \mathrm{~V}$; (c) $V_{l}$ and $V_{c o}$ when $V_{a c}=85 \mathrm{~V}$; (d) $V_{\text {out }}$, $I_{\text {out }}$, and $I_{o}$ when $V_{a c}=85 \mathrm{~V}$; (e) detailed $V_{\text {out }}$ when $V_{a c}=85 \mathrm{~V}$; (f) detailed $I_{\text {out }}$ when $V_{a c}=85 \mathrm{~V}$; $(\mathrm{g})$ detailed $I_{o}$ when $V_{a c}=85 \mathrm{~V}$; and (h) input power of flyback de-de converter $P_{\text {in }}$ versus input voltage $V_{c o}$.

According to the results, the following conclusions can be obtained. Firstly, as the parasitical resistance in the input circuit is very small and has little influence on the charging current to the filter capacitance, the processes of charging and discharging of the input filter capacitor are independent, and the boundary is near the maximal value of input voltage. Secondly, the input power of flyback dcdc converter under different input alternating voltages can be seen as an approximately constant power load. Thirdly, according to the place pointed by arrows 1 and 2 in Fig. $3(\mathrm{~d})-(\mathrm{f})$, it is found that when the voltage $V_{c 0}$ goes below the minimal voltage $V_{\text {lmin }}=102 \mathrm{~V}$ of flyback dc-dc converter, the output voltage of the converter with the rated load is smaller than the rated output voltage of $5 \mathrm{~V}$. This also has strong impact on other performances of converters. It indicates that the adopted $C_{0}$ is not large enough.

If ignoring the impact of the resistor $R_{0}$, according to the above three conclusions, the minimal value of the input filter capacitance $C_{0 \text { min }}$ can be approximately decided by the following equation:

$$
C_{0 \text { min }}=\frac{2 P_{i n}\left[\frac{T}{4}+\arcsin \left(\frac{V_{1 \text { min }}}{\sqrt{2} V_{a c \text { min }}}\right)\right]}{2 V_{a c \text { min }}^{2}-V_{1 \text { min }}^{2}}
$$

where $T$ is the period of the input alternating voltage ( $0.02 \mathrm{~s}$ here), and $V_{a c m i n}$ is the minimal input alternating voltage of flyback ac-dc converter ( $V_{a c}=85 \mathrm{~V}$ here).

\section{ANALYTIC METHOD FOR DECIDING THE INPUT FILTER CAPACITANCE IN FlybaCK AC-DC CONVERTER}

In fact, the analytical method for deciding the input filter capacitance in flyback ac-dc converter has been given as (1). The only question left to be solved is the lack of theoretical verification that the input power of the flyback dc-dc converter can be seen as constant under different input dc voltages, even although it has been proved in a way by the simulation results shown in Fig. 3(h). For this, three parts of work are included in this section.

\section{A. Theoretical Deduction under Ideal Assumptions}

As an analytic method is often built based on the assumptions that all the electronic parts are ideal, the following assumptions and simplifications are made:

(1) The power MOSFET in the ON state is modeled by a zero resistance and in the OFF state by an infinite resistance, $R_{I N F}$. The output capacitance and inductance of the leading wires are ignored.

(2) The diode in the ON state is modeled by a constant voltage source, $V_{F}$, and in the OFF state by an infinite resistance. The diode junction capacitance is negligible.

(3) All the leakage inductances and stray capacitances of the transformer are neglected.

(4) Passive components are linear, time invariant, and frequency independent.

Then the equivalent circuit of flyback dc-dc converter (a buck-boost dc-dc converter) is obtained and shown in Fig. 4.

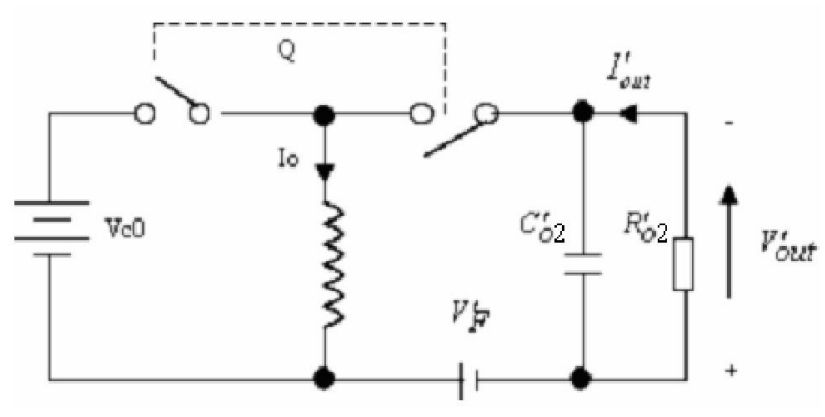

Fig. 4. Typical buck-boost converter circuit

The parameters of the secondary winding are referred to the primary side by 
$V_{F}^{\prime}=\frac{N 1}{N 2} V_{F}, C_{o 2}^{\prime}=\left(\frac{N 2}{N 1}\right)^{2} C_{o 2}$ and $V_{o u t}^{\prime}=\frac{N 1}{N 2} V_{o u t}$

where $N 1$ and $N 2$ are the numbers of turns of the primary and secondary windings of the transformer, respectively.

Because the operation state of dc-dc converter with the rated load and the maximal input de voltage $V_{1 \max }$ is often designed as the critical conduction mode, which can be processed as a special continuous conduction mode (CCM), then according to the analysis in [2], all the operation state with the rated load is CCM in the full input voltage range.

According to Fig. 4, the following equation can be obtained:

$$
d I_{o}=\frac{V_{c 0}}{L_{1}} D T=\frac{V_{o u t}^{\prime}+V_{F}^{\prime}}{L_{1}}(1-D) T
$$

where $I_{o}$ is the current in the primary winding of the transformer, $V_{c 0}$ is the input voltage, $L_{1}$ is the primary winding inductance, $D$ is the duty ratio, and $T$ is the time period of a duty cycle. From (2), the duty ratio can be calculated by

$$
D=\frac{V_{o u t}^{\prime}+V_{F}^{\prime}}{V_{o u t}^{\prime}+V_{F}^{\prime}+V_{c 0}}
$$

The duty ratio of PWM only depends on the equivalent input voltage, equivalent voltage source of diode and output voltage; it is not affected by the load and the inductance.

According to the output equation during one period, i.e. $d V_{\text {out }}^{\prime}=0$, the following equations are obtained:

$$
\begin{aligned}
& \frac{i_{o}-i_{\text {out }}^{\prime}}{C_{o 2}^{\prime}}(1-D) T=\frac{i_{\text {out }}^{\prime}}{C_{o 2}^{\prime}} D T \\
& i_{o}=i_{\text {out }}^{\prime} /(1-D) \\
& P_{D T}=V_{F}^{\prime} i_{o}(1-D)=V_{F}^{\prime} i_{\text {out }}^{\prime} \\
& P_{\text {out }}=V_{\text {out }}^{\prime} i_{\text {out }}^{\prime}
\end{aligned}
$$

where $P_{D T}$ is the steady-state power loss of diode D1, and $P_{\text {out }}$ is the rated output power of the converter. As only two parts $\left(R_{O}^{\prime}\right.$ and $\left.V_{F}^{\prime}\right)$ in Fig. 2 can consume power, the input power of the dc-dc converter can be calculated by

$$
P_{\text {in }}=P_{D T}+P_{\text {out }}=\left(V_{F}^{\prime}+V_{\text {out }}^{\prime}\right) i_{\text {out }}^{\prime}
$$

With the rated output load, all the variables of $V_{F}^{\prime}$, $V_{\text {out }}^{\prime}$, and $i_{\text {out }}^{\prime}$ are constant, so the input power of the converter $P_{\text {in }}$ is also constant. This gives the theoretical verification that the input power of the flyback dc-dc converter can be seen as constant.

\section{B. Impact on the Input Power by Parasitical Parameters in Actual Electronic Parts}

Although there are many parasitical parameters in the converter, according to [3-4] and Fig. 1, the main parasitical parameters, which have heavy influence on the total power loss $P_{z}$, are constituted by five parts: the power loss in the transformer, $P_{c u-f e}$, the power loss in the snubber circuit of $\mathrm{R}_{2} \mathrm{C}_{2} \mathrm{D}_{2}, P_{r c d}$, the switching power loss, $P_{m s}$, which also includes the power loss consumed by the current sensor resistor, $\mathrm{R}_{\mathrm{s}}$, the power loss of $V_{F}$ in diode D1, $P_{D T}$, and the power loss of $R_{F}$ in diode D1, $P_{R T}$. Before the further analysis, the following assumptions and simplifications are made:

(1) The transient process of switching ON and OFF is omitted, and then the switching power loss $P_{m s}$ just takes the power loss consumed by the resistance $R_{M O N}$ of MOSFET in conducting state and $R_{s}$.

(2) Considering that all the leakage inductance and resistance in the transformer, the diode conducting resistor $R_{D O N}$ and the resistors $R_{M O N}$ and $R_{S}$ have small influence on the duty cycle ratio $D$, so the duty cycle ratio can still be calculated by (3). Furthermore, all the energy in leakage inductance is approximately equal to that absorbed by the snubber circuit of $\mathrm{R}_{2} \mathrm{C}_{2} \mathrm{D}_{2}$.

(3) Except for the power loss $P_{D T}$, as the sum of all the other power losses is very small, in order to simplify their calculation, all the currents here are considered by their average values.

Based on the above assumptions, the power losses can be obtained by the following equation group

$\left\{\begin{array}{l}P_{c u-f e}=\left(\frac{i_{\text {out }}^{\prime}}{1-D}\right)^{2} r_{1}+P_{f e} \\ P_{R T}=i_{\text {out }}^{\prime 2} R_{D O N}^{2}\left(\frac{N_{1}}{N_{2}}\right)^{2} \\ P_{D T}=V_{F}^{\prime} i_{\text {out }}^{\prime} \\ P_{r c d}=\frac{L_{s} i_{\text {out }}^{\prime} V_{c 0}}{L_{1}+L_{s}} \frac{D}{1-D} \\ P_{m s}=\left(\frac{i_{\text {out }}^{\prime}}{1-D}\right)^{2}\left(R_{M O N}+R_{S}\right) D\end{array}\right.$

where $r_{1}$ is the resistance of the primary winding of the transformer, and $P_{f e}$ is the core loss in the transformer with rated specifications, including eddy current loss, hysteresis loss and anomalous loss. According to the analysis in [5], the core loss can be seen as approximately constant.

As the duty cycle ratio is calculated by (3), all kinds of power loss in (9) can be calculated analytically. Along with (10) and (11), the total power loss $P_{z}$ and the input power $P_{\text {in }}$ can also be calculated analytically.

$$
\begin{aligned}
& P_{z}=P_{c u-f e}+P_{R T}+P_{D T}+P_{r c d}+P_{m s} \\
& P_{\text {in }}=P_{\text {out }}+P_{Z}=V_{\text {out }}^{\prime} i_{\text {out }}^{\prime}+P_{Z}
\end{aligned}
$$

From (9) and (10), it is easy to find that when the input voltage $V_{c o}$ decreases, the total power loss $P_{z}$ will increase. This is consistent with that shown in Fig. 3(h). By replacing the input power $P_{\text {in }}$ in (1) with (11), the minimal input filter capacitance with higher accuracy is 
obtained. It should be pointed out that according to (3), the power loss of diode D1 takes about $60 \%$ of total power loss, and so the input power is approximately constant with different input voltages.

\section{Influence Caused by Control Delay}

For the flyback dc-dc converter with peak currentcontrolled mode, the maximum current of $I_{o}$ is often decided at the minimal input voltage $V_{1 \text { min }}$. However, the circuit of $\mathrm{RC}$ filter such as $\mathrm{R}_{4}$ and $\mathrm{C}_{3}$, and transferring delay of switching control integrated chip (IC) will increase the influence on the maximum current of $I_{o}$. This ensures that the minimal value of $\mathrm{C}_{\mathrm{o}}$ obtained from (1) can also satisfy the requirement of system output ability. As introduced in [1], for being limited by system reliability, the control delay caused by $\mathrm{RC}$ filter has been minimized, so its impact on the minimal value of $C_{o}$ is very limited.

\section{CONClusions}

This paper has presented a general method for deciding the input filter capacitance of flyback switching ac-dc converters with peak current-controlled model. Both numerical method and analytical method are given. Both the simulation results and theoretical deduction prove that the flyback dc-dc converter can be considered as a constant power load. The effects of parasitical parameters and control delay in the electronic parts are studied, and the corresponding analytical method for deciding the input filter capacitance is given. The impact on the capacitance caused by the control delay is analyzed qualitatively.

\section{REFERENCES}

[1] J. X. Chen, J. G. Zhu, Y. G. Guo, and J. X. Jin, "Modeling and simulation of flyback DC-DC converter under heavy load," in Proc. IEEE Int. Conf. on Communications, Circuits and Systems, Guilin, China, 25-28 June 2006, vol. 4, pp. 2757-2761.

[2] J. X. Chen, J. G. Zhu, and Y. G. Guo, "Calculation of power loss in output diode of a flyback switching DC-DC converter," in Proc. ICES/IEEE Int. Conf. on Power Electronics and Motion Control, Shanghai, China, 13-16 August 2006, vol. 1, pp. 1-5.

[3] Marty Brown, Power Supply Cookbook. $2^{\text {nd }}$ Edition. England: Elsevier Science Ltd., 2001.

[4] Z. S. Zhang and X. S. Cai, Theory and Design of Switching Converters (in Chinese). Beijing: Electronics Industry Publishing Company, 1999.

[5] J. X. Chen, Y. G. Guo, and J. G. Zhu, "A generalized dynamic model for flyback switching converter based on nonlinear finite element analysis," in Proc. IET Int. Conf. on Technology and Innovation, Hangzhou, China, 6-8 November 2006, vol. 1, pp. 1-6. 